\title{
Analisa Kerusakan Poros Motor Final Drive dan Solusi Pemeliharaan pada Unit Excavator 220 LC
}

\author{
Veny Selviyanty. YH \\ Jurusan Teknik Mesin, Sekolah Tinggi Teknologi Pekanbaru \\ E-mail : venyselviyanty@gmail.com
}

\begin{abstract}
Abstrak
Final drive adalah susunan gigi yang biasanya dalam bentuk satu set roda gigi dan lurus atau satu set gigi planet (planetary gear) sebagai drive final gear yang berfungsi untuk mengurangi rotasi dan meningkatkan torsi satuan. Prinsip kerja final drive bersama-sama dengan prinsip-prinsip transmisi, di mana ada pengurangan kecepatan rotasi dan meningkatkan torsi dengan memanfaatkan perbedaan jumlah gigi pada gigi. Pada saat operasi dan drive gigi spline gigi rusak kerusakan / permukaan (memakai / aus dan deformasi). Tujuan dari penelitian ini adalah untuk menentukan penyebab kerusakan gigi drive dan gigi spline shaft motor final drive $220 \mathrm{LC}$ excavator dan untuk mencegah kerusakan serupa di masa mendatang. Dari data pengujian menyimpulkan bahwa kerusakan pada gigi drive dan gigi spline poros motor akhir perjalanan excavator 220 LC adalah memakai lelah (fatigue memakai) dan kegagalan lelah (kegagalan fatigue) yang disebabkan oleh adanya gaya tekan berulang kali (beban dinamis) dan gesekan rotary menyebabkan beban kelelahan di permukaan.
\end{abstract}

Kata kunci : Final Drive, kerusakan permukaan, memakai kelelahan, kegagalan kelelahan, beban dinamis

\begin{abstract}
Final drive is an arrangement of gears that are usually in the form of a set of gears and a straight or a set of planetary gears (planetary gear) as the final drive gear which serves to reduce the rotation and torque boost unit. The working principle of the final drive together with the principles of the transmission, where there is a reduction in rotational speed and increase torque by exploiting differences in the number of teeth on the gear. At the time of operation and the drive gear spline gear damaged / surface damage (wear / wear and deformation). The purpose of this study was to determine the cause of the damage to the drive gear and gear spline shaft final drive motors 220 LC excavator and to prevent similar damage in future. From the test data concluded that damage to the drive gear and gear spline motor shaft final drive excavator $220 \mathrm{LC}$ is wear tired (fatigue wear) and the failure of tired (fatigue failure) caused by the presence of compressive force repeatedly (dynamic load) and rotary friction causes fatigue loads on the surface.
\end{abstract}

Keywords: Final drive, surface damage, fatigue wear, fatigue failure, the load dynamic

\section{Pendahuluan}

Excavator merupakan salah satu peralatan yang penting dalam pekerjaan pemindah tanah (earth moving), karena fungsinya yang serba guna yaitu disamping sebagai alat penggali dan pemindah, juga berfungsi sebagai alat pemuat (loader), alat pengangkat (lifting) dan sebagai alat pemecah (breaker) bila pada attachment nya dilengkapi dengan perlengkapan yang tepat dan sesuai dengan pekerjaan.

Sekitar pertengahan bulan Maret 2012, telah terjadi kerusakan pada komponen system pembangkit tenaga dari kendaraan alat berat
(Excavator) milik PEMDA KAMPAR di Bangkinang. Kerusakan komponen system pembangkit tenaga tersebut tepatnya pada poros atau shaft final drive. Excavator tersebut digunakan untuk perbaikan jalan.

Dari informasi yang diperoleh diketahui bahwa shaft final drive atau dalam hal ini Excavator dioperasikan tahun 2007 dan kerusakan terjadi sekitar pertengahan bulan Maret 2012 atau telah dipakai selama 5 tahun. Final drive dipasang melebar keluar dari badan unit setelah steering clutch. 


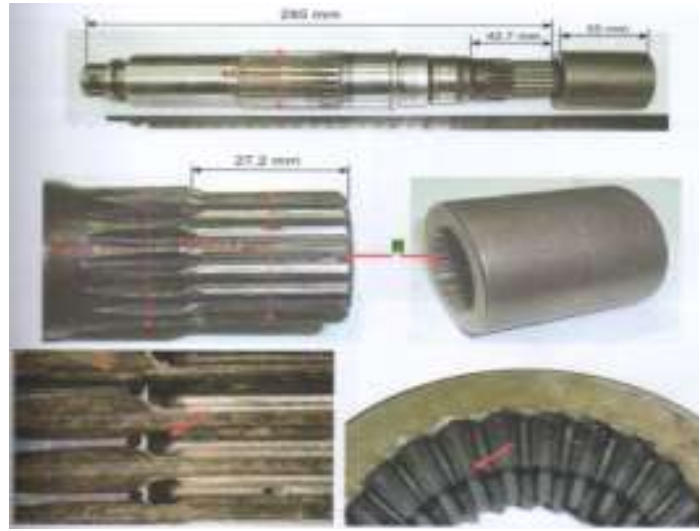

Gambar 1. Dokumentasi kerusakan Final drive shaft excavator yang mengalami kerusakan pada gigi penggerak dan pada roda gigi spline

Kerusakan pada travel motor mempengaruhi kinerja unit tersebut, yang sering terjadi yaitu low pressure atau lemahnya tekanan pada travel motor, sehingga final drive susah untuk berputar. Troubleshooting pada travel motor bertujuan untuk memperbaiki kerusakan yang terjadi. Dalam proses perbaikan, harus dilakukan sesuai dengan prosedur troubleshooting agar root couse permasalahan dapat ditemukan.

Telah terjadi kerusakan dan kegagalan pada poros motor final drive excavator 220 LC yang belum diketahui penyebab pastinya, untuk itu perlu pengkajian ilmiah dan uji laboratorium agar peristiwa dapat diketahui dengan jelas penyebabnya, dengan melakukan identifikasi, inventegasi meliputi sistem dan prosedur pengoperasian, perawatan, pengujian laboratorium terhadap gaya dan material (macrostruktur, microstruktur, pengujian beban pada penampang dan patahan), berdasarkan data analisis tersebut penyebab kerusakan dan kegagalan dapat terungkap.

Lingkup penelitian ini dibatasi hanya pada penelitian untuk mengetahui penyebab utama terjadinya surface damage ( aus/wear dan deformasi) pada gigi penggerak dan pada roda gigi spline dan mekanisme terjadinya surface damage tersebut serta menjawab kejadian yang dianggap sebagai pemicu kerusakan dan kegagalan pada gigi penggerak dan roda gigi spline poros motor final drive excavator tersebut.

Tujuan penelitian ini adalah untuk menentukan penyebab terjadinya kerusakan pada gigi penggerak dan roda gigi spline poros motor final drive excavator 220 LC dan untuk mencegah terjadinya kerusakan yang sama diwaktu mendatang.

\subsection{Excavator}

Excavator merupakan salah satu alat berat yang digunakan untuk memindahkan material. Excavator banyak digunakan untuk :

1. Menggali parit, lubang, dan pondasi.

2. Penghancuran gedung.

3. Meratakan permukaan tanah.

4. Mengangkat dan memindahkan material.

5. Mengeruk sungai.

6. Pertambangan.

Beberapa bidang industri yang menggunakannya antara lain konstruksi, pertambangan, infrastruktur dan sebagainya.

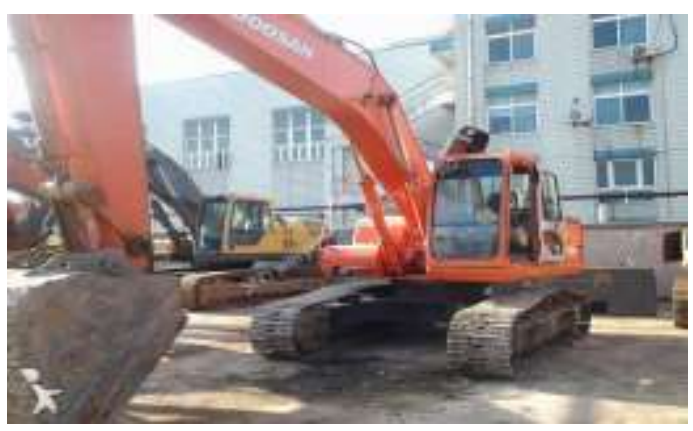

Gambar 2. Excavator

\subsection{Pengertian dan Fungsi Final Drive}

Secara umumfinal drive adalah susunan roda gigi yang biasanya berupa satu set roda gigi lurus dan atau satu set roda gigi planet (planetary gear) sebagai roda gigi penggerak akhir yang berfungsi untuk mereduksi putaran dan meningkatkan torsi unit, seperti pada bulldozer, dump truck, wheel loader, dan lainlain.

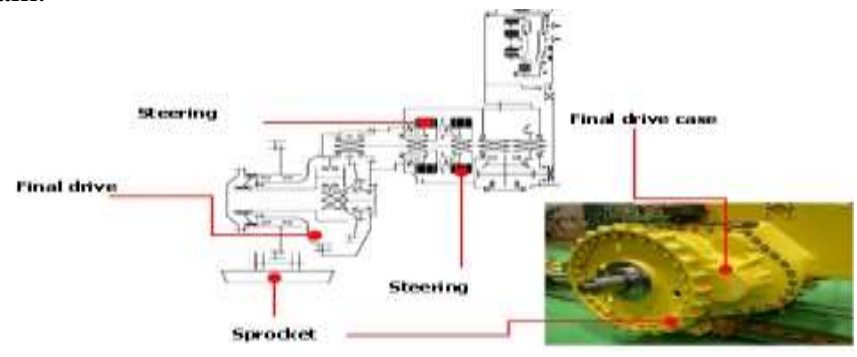

Gambar 3. Prinsip dasar final drive

\subsection{Prinsip Dasar Final Drive}

Prinsip yang dipergunakan pada transmisi dimana kecepatan rotasi dikurangi dan momen puntir ( torque ) ditambah oleh sejumlah roda gigi yang dipergunakan pada penggerak akhir. Masing-masing bak penggerak akhir (final drive case) dipasang melebar keluar dari bak roda gigi tirus ( bevel gear case) pada masing-masing sisi. Dengan memilih perbandingan kecepatan yang tepat momen puntir (Torque) sebelum ke 
penggerak akhir (final drive) dapat diperkecil. Dengan demikian, transmisi yang sama, poros roda tirus ( bevel gear shaft) dan lain-lain dapat dipergunakan yang sama pada berbagai jenis model mesin.

Roda gigi penggerak akhir ( final Drive gears) dapat dihadapkan pada tekanan permukaan yang besar disebabkan oleh beban goncangan dan benturan (shock and impact loads), yang mana memerlukan perhatian ekstra untuk seleksi oli pelumas dan mencegah masuknya benda asing ke dalam bak penggerak akhir (final drive cases).

Perbandingan reduksi normal berada diantara 1/9 sampai 1/12 untuk perbandingan reduksi yang lebih kecil dipergunakan sistem reduksi tunggal (single reduction system). Untuk perbandingan reduksi yang besar dipergunakan sistem reduksi ganda atau sistem roda gigi planet. (Double reduction system or planetary gear system ).

\subsection{Analisa Kerusakan (Failure Analysis)}

Kerusakan dapat didefinisikan sebagai suatu perubahan komponen dan struktur mesin atau peralatan produksi sedemikian rupa, sehingga mereka tidak mampu melaksanakan fungsi sebenarnya secara memuaskan.

Suatu komponen atau struktur dapat di nyatakan atau dipandang rusak apabila memenuhi salah satu dari tiga kondisi sebagai berikut : Bila komponen, peralatan atau konstruksi secara keseluruhan tidak mampu lagi dioperasikan, Bila komponen, peralatan atau konstruksi masih mampu di operasikan, tetapi tidak mampu lebih lama lagi untuk melaksanakan fungsi seperti yang di harapkan dengan memuaskan,atau bila komponen, peralatan atau struktur dalam kondisi sangat buruk sehingga tidak dapat di andalkan atau tidak aman lagi untuk dioperasikan, oleh karna itu bagian yang rusak hars diperbaiki atau diganti.

\subsection{Pokok - Pokok Analisa Kerusakan}

Menentukan kronologis kejadian dan hubungan dari setiap kejadian sampai timbulnya kerusakan diidentifikasi, pengumpulan dan pengolahan data atau informasi untuk menentukan penyebab utama kerusakan dengan : Fraktografi, Metalografi, Uji Kekerasan dan Uji Komposisi Kimia.

\subsection{Remaining Life Assessment}

Peralatan industri selalu dirancang untuk dapat dipakai secara aman dalam jangka waktu tertentu. Jika umur operasi telah tercapai namun dianggap peralatan masih memiliki unjuk kerja yang andal, maka peralatan tersebut masih dimungkinkan bisa diperpanjang umur operasinya. "Remaining life assessment" adalah suatu aktivitas untuk melakukan analisis secara komprehensif terhadap peralatan yang telah "aging" namun diperkirakan masih memiliki unjuk kerja yang andal. Selanjutnya hasil analisis akan dijadikan dasar untuk menentukan kelayakan perpanjangan umur operasi mesin / peralatan tersebut. Dengan dilakukannya perpanjangan umur peralatan mesin secara aman, tentu akan dapat mengurangi beban operasi mesin, yang pada gilirannya akan dapat menurunkan harga produk di pasaran.

Kegiatan Failure analysis ditujukan untuk mengetahui penyebab kerusakan yang spesifik dari peralatan, pelengkap dan intalasi mesin serta untuk menentukan tindakan pencegahan agar kerusakan tidak terulang. Manfaat dari analisis kegagalan ini dalam jangka pendek diharapkan dapat memperbaiki desain, proses dan metode pabrik. Dalam jangka panjang dapat dipakai untuk pengembangan material dan sebagai metode mutakhir untuk evaluasi dan memprediksi performance material serta untuk memperbaiki system pemeliharaan.

\subsection{Mekanisme Kerusakan}

Mekanisme kerusakan meliputi hal sebagai berukut :

a. Kerusakan terjadi karena cracking atau korosi atau kombinasi keduanya

b. Umumnya kerusakan terjadi bertahap (gradual).

c. Pecah atau kerusakan tiba-tiba dapat pula terjadi dan biasanya disebabkan oleh sifat getas-takik (notchbrittle)

Kerusakan akibat cracking terjadi melalui 3 tahap :

1. Initiation

Crack Initiation

Retak awal (initial-crack) dapat mencapai ukuran submikroskopik, ukuran ikroskopik, atau bahkan visible

2. Growth

Crack Growth

Permulaan dan perpanjangan retak hingga mencapai suatu ukuran kritis disebut mencapai tahap initial growth.

3. Propagation

Crak Propagation

Tahap penjalaran retak (crack propagation) meliputi unstable stage diluar tahapan growth, bila perpanjangan retak menjadi lebih cepat (bisa kontinyu atau terputus-putus).

1.8. Analisis Kegagalan 
Kegagalan dapat didefenisikan sebagai kejadian sewaktu komponen tidak lagi mampu memenuhi fungsi pemakaiannya dengan baik dikerenakan patahan atau deformasi berlebih ataupun deteriorasi. Mekanisme kegagalan umumnya merupakan kegagalan bahan yang ditentukan oleh riwayat termomekanis bahan selama pemrosesan dan kondisi pemakaian. Tahap - tahap yang mendahului kegagalan akhir adalah kegagalan dini, kerusakan dini semua ini akan membuat bagian atau komponennya menjadi tidak aman untuk pemakaian berikutnya.

\section{Methodologi}

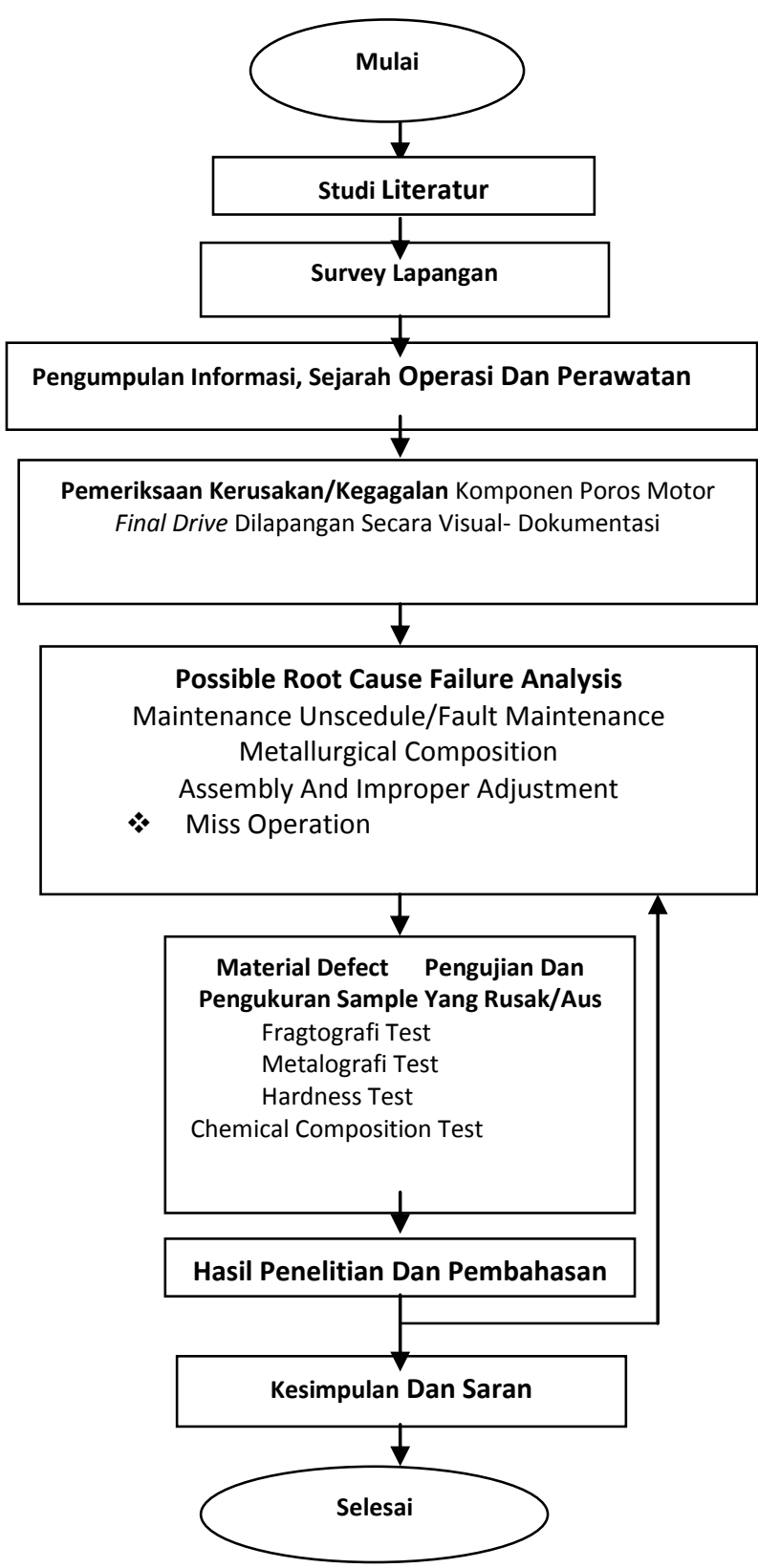

Gambar 4:. Metodologi penelitian
Pengambilan data serta sampel / material pengujian dilakukan di workshop Pemda Kampar, dan pengujian material dilakukan di B2TKS - BPPT untuk pengujian Fraktografi, Metalografi, Uji Kekerasan serta Komposisi Kimia.

Waktu pelaksanaan penelitian serta pengujian dilaksanakan selama 6 (enam) bulan.

Bahan yang digunakan pada penelitian ini adalah Poros Motor Final Drive Excavator 220 $L C$ (gigi penggerak dan roda gigi spline) buatan pabrikan yang mengalami surface damage (aus/wear dan deformasi).

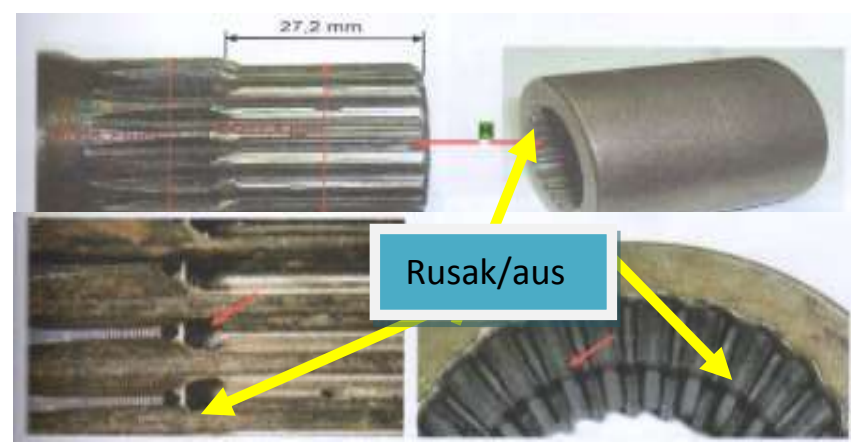

Gambar 5. Gigi penggerak dan roda gigi spline yang mengalami surface damage (aus/wear dan deformasi).

\section{Peralatan dan metode}

Untuk pengujian fraktografi, metalografi, uji kekerasan serta komposisi kimia serta SEM peralatan yang digunakan antara lain : Peralatan Grinding dan Polishing, Hardness tester "Frank Finotest”, Mikroskop optik dan kamera digital, Bahan habis pakai seperti: Kertas amplas dengan berbagai ukuran, pasta diamond dan bahan kimia untuk etsa, Spectroanalyse PMIMaster-Pro.

\section{Hasil dan Pembahasan}

Berdasarkan informasi dari operator serta mekanik yang menangani unit excavator tersebut diperoleh data sebagai berikut : Siklus pengantian oli pelumas tidak sesuai dari jadwal yang telah ditentukan sesuai dengan buku petunjuk pabrik pembuat, Pada saat beroperasi, unit sering melakukan rolling (pindah lokasi kerja) terlalu jauh lebih kurang $40 \mathrm{~km}$ ( \pm 3 hari), Unit excavator termasuk long crawler (tipe LC) untuk excavator tipe berat 22 ton, Unit excavator ini sebelumnya telah mengalami kerusakan yang sama diposisi yang berbeda, awal kerusakan terjadi disebelah kanan unit, dan pada saat penulis melakukan penelitian ini unit mengalami kerusakan diposisi sebelah kiri. 
Poros motor final drive excavator (gigi penggerak dan roda gigi spline) mengalami kerusakan, jenis kerusakan: surface damage ( aus/wear dan deformasi).

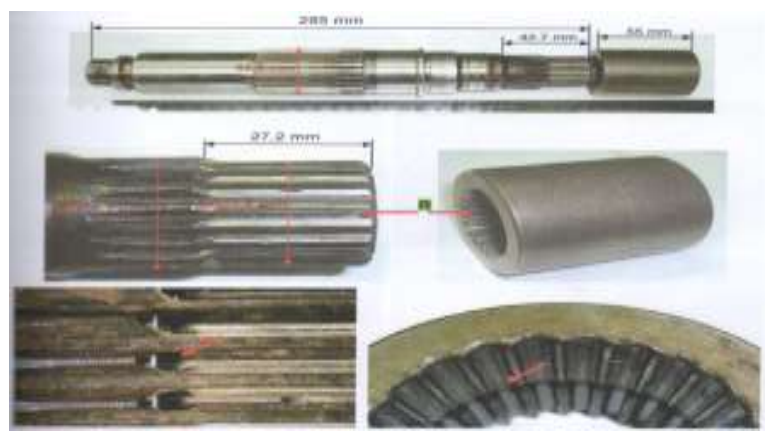

Gambar 6. Poros motor final drive (gigi penggerak dan roda gigi spline) yang mengalami kerusakan / keausan

Berdasarkan temuan serta gambar diatas terlihat bahwa pada gigi penggerak dan pada roda gigi spline mengalami kerusakan / surface damage ( aus/wear dan deformasi) akibat gesekan beban putar.

\subsection{Analisa penyebab kerusakan pada poros motor final drive (gigi penggerak dan roda gigi spline)}

Seperti yang di ketahui final drive adalah suatu komponen dari sistem pemindah tenaga yang berfungsi sebagai penggerak akhir pada suatu unit dan juga sebagai pendukung berat unit karena final drive tersebut langsung terpasang dengan track sehingga sebagian besar bobot unit juga akan mempengaruhi kinerja dari final drive tersebut pada saat unit dalam beroperasi. Trouble yang di temukan adalah dimana komponen poros motor final drive dari unit excavator $220 \quad L C$ yang teridentifikasi mengalami kerusakan / keausan, setelah di lakukan proses disassembly. Bagian-bagian inner part yang mengalami kerusakan adalah gigi penggerak dan roda gigi spline.

Rupture (putus, patah) force rupture adalah jenis kerusakan yang di sebabkan oleh aplikasi beban satu arah secara tiba-tiba. Fatigue rupture ( $70 \%$ penyebab kerusakan pada metal part), maksudnya adalah kerusakan dimana patahan dari crack yang membesar secara perlahan akibat aplikasi beban berulang-ulang dalam waktu yang lama. Sedangkan surface deformation (kerusakan permukaan) dimana ada bagian wear adalah berkurangnya lapisan material kontak antara 2 permukaan atau lebih, surface fatigue adalah terkelupasnya permukaan akibat oleh stress yang melebihi batas lelah dan plastic yielding adalah akibat beban yang besar. Pada dasarnya final drive poros motor adalah tipe planetary gear, yang dapat bekerja jika di beri input putaran dan salah satu komponennya harus di tahan. Power dari engine di teruskan ke transmisi kemudian oleh pertautan bevel gear pinion yang memutar bevel gear akan menghasilkan putaran lebih besar dari pinion bevel gear, selanjutnnya putaran akan di teruskan melalui shaft sun gear ke planetary yang mana fungsi sun gear memutar planetry agar mereduksi putaran kemudian output shaft meneruskan putaran menuju sprocket.

3.2. Analisa hasil pemeriksaan visual terhadap bentuk poros motor dan gear final drive dan coupling

Pemeriksaan ini diawali dengan pemeriksaan secara visual yaitu pemeriksaan secara langsung dari poros motor final drive yang mengalami kerusakan, terutama pada permukaan patahan. Pengamatan visual ini sangat penting dilakukan sebelum melangkah mendeteksi bentuk atau ciri kegagalan yang dialami oleh poros final drive.

Pemeriksaan secara visual pada poros yang mengalami kerusakan meliputi :

- Pengambilan gambar foto dari berbagai arah.

- Mengekspos posisi-posisi penting sebagai identifikasi informasi kerusakan.
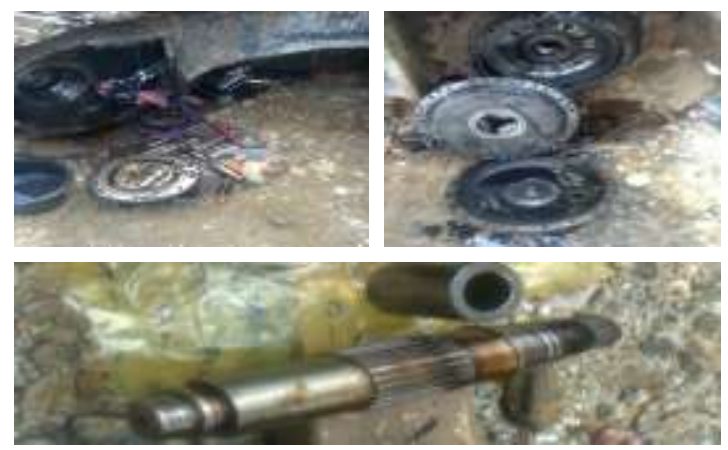

Gambar 7. Shaft/gear final drive dan coupling
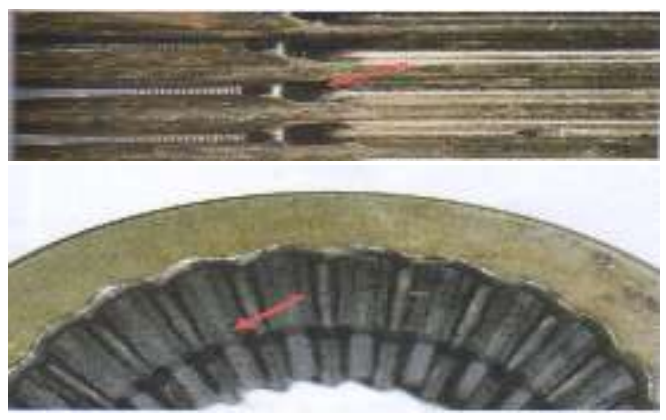

Gambar 8. Kerusakan gigi penggerak dan roda gigi spline 
Hasil pemeriksaan visual dengan foto makro gigi penggerak dan roda gigi spline terlihat bahwa pada gigi penggerak mengalami keausan akibat gesekan beban putar, dan pada roda gigi spline terlihat adanya serpihan patah akibat beban gesek.

3.3. Hasil pengujian komposisi kimia ( chemical composition)

Objek : Gigi penggerak dan roda gigi spline

Bahan : Steel

Mesin Uji : Arc-Spark Spektrometer

Standar Uji : ASTM A 751

Tabel 1.

Hasil Pengujian Komposisi Kimia

\begin{tabular}{ccc}
\hline \multirow{2}{*}{ Unsur } & \multicolumn{2}{c}{ Komposisi Kimia Unsur (\%) } \\
\cline { 2 - 3 } & Gigi Penggerak & Roda Gigi Spline \\
\hline $\mathrm{Fe}$ & 97,2 & 97,4 \\
$\mathrm{C}$ & 0,392 & 0,257 \\
$\mathrm{Si}$ & 0,212 & 0,261 \\
$\mathrm{Mn}$ & 0,760 & 0,709 \\
$\mathrm{Cr}$ & 1,03 & 1,03 \\
$\mathrm{Ni}$ & 0,0362 & 0,0466 \\
$\mathrm{Mo}$ & 0,191 & 0,188 \\
$\mathrm{Cu}$ & 0,0546 & 0,0674 \\
$\mathrm{Al}$ & 0,0145 & 0,0035 \\
$\mathrm{~V}$ & 0,0081 & 0,0109 \\
$\mathrm{~W}$ & 0,0250 & 0,0250 \\
$\mathrm{Ti}$ & 0,0019 & 0,0035 \\
$\mathrm{Nb}$ & 0,0106 & 0,0064 \\
$\mathrm{~B}$ & 0,0010 & 0,0010 \\
$\mathrm{~S}$ & 0,0126 & 0,0085 \\
$\mathrm{P}$ & 0,0188 & 0,0193 \\
\hline
\end{tabular}

Dengan komposisi kimia seperti tabel diatas diketahui bahwa gigi penggerak terbuat dari Baja Paduan Rendah (Low Alloy Steel), termasuk dalam kelompok Baja AISI 4140 (Through-Hardening Low Alloy Steel Bar).

\subsection{Pengujian visual / makrografi}

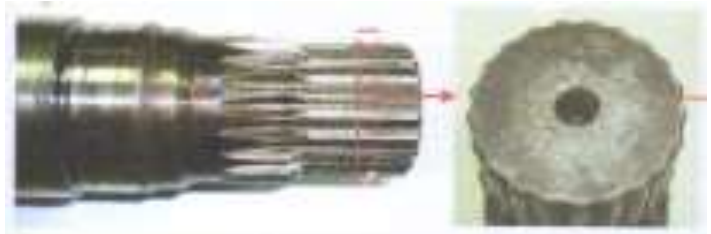

Gambar 9. Kerusakan roda gigi penggerak yang mengalami keausan akibat gesekan beban putar

Pengujian visual/ makro dilakukan dengan mengamati permukaan / puncak gigi penggerak yang mengalami kerusakan / keausan, dengan hasil sebagai berikut :

\subsection{Hasil pengujian makrografi roda gigi} penggerak yang mengalami kerusakan

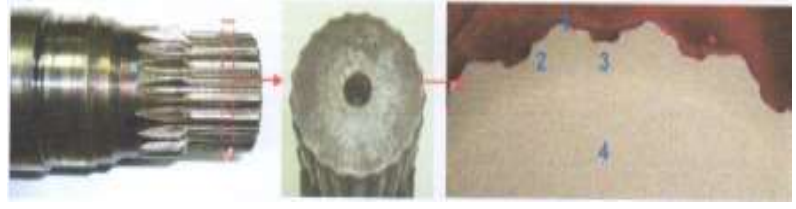

Gambar 10: Bentuk struktur mikro kerusakan roda gigi penggerak yang mengalami aus akibat gesekan beban putar didaerah gigi (lokasi 1,2 dan 3) berupa martensit dan dibagian tengah berupa bainit-martensit (lokasi 4), terdapat cacat inklusi Etsa: nital 2\%

Berdasarkan hasil pengujian struktur mikro seperti terlihat. diatas telah terjadi keausan pada daerah gigi lokasi 1, 2 dan 3 akibat gesekan beban putar berupa martensit dan pada lokasi 4 terdapat cacat inklusi yaitu disebabkan oleh pengotor (inklusi) baik berupa produk karena reaksi gas atau berupa unsur-unsur dari luar seperti: terak, oksida, logam wolfram, atau lainnya. Cacat ini biasanya terjadi pada daerah bagian logam las (weld metal).

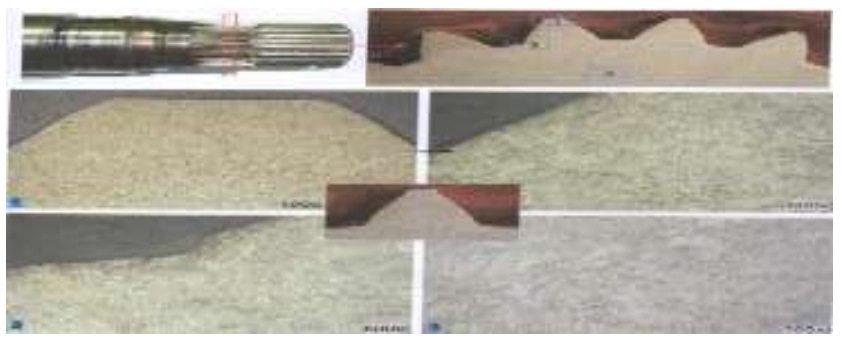

Gambar 11. Struktur mikro daerah puncak roda gigi dan kaki roda gig yang tidak mengalami kerusakan berupa martensit dan dibagian tengah berupa martensit - bainit Etsa: nital 2\%

Pada gambar 12 (pembesaran 100 dan 500 x) terlihat bahwa struktur mikro yang terjadi berupa martensit halus dengan butir karbida crome menyebar merata pada daerah yang dikeraskan. Pengerasan permukaan (case hardening) dapat dikatakan sebagai proses laku panas untuk memperoleh kekerasan hanya pada permukaannya saja, atau dengan kata lain lapisan permukaan mempunyai kekerasan yang lebih tinggi sedangkan bagian yang lebih dalam tetap seperti semula (kekerasan rendah tetapi keuletannya tinggi). Dalam kondisi ini pada lapisan permukaan terdapat tegangan sisa yang berupa tegangan tekan (tahan terhadap kelelahan, fatique limitnya naik) dan secara keseluruhan material tersebut masih ulet.

Peningkatan temperatur (suhu tinggi) pada permukaan baja diperoleh akibat terjadinya gesekan dan beban putar antara gigi penggerak dan roda gigi spline, pada saat beroperasi sehingga menimbulkan transformasi fasa.

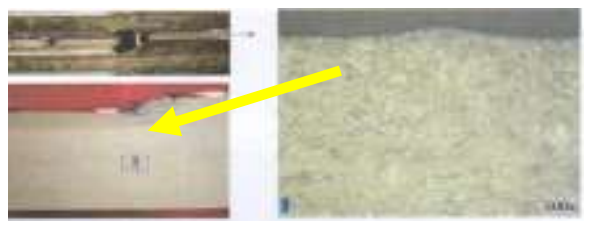




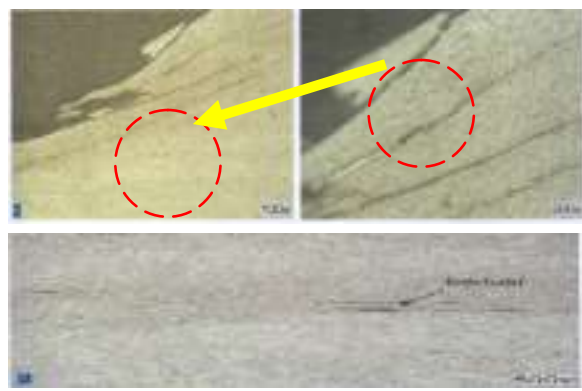

Gambar 12. Struktur mikro daerah antara yang rusak dan tidak rusak puncak roda gigi dan kaki roda gigi

Berdasarkan hasil pengujian struktur mikro diidentifikasikan pada lokasi 2 menunjukkan serpihan patah/lipatan akibat beban gesek putar

\section{Gigi Spline}

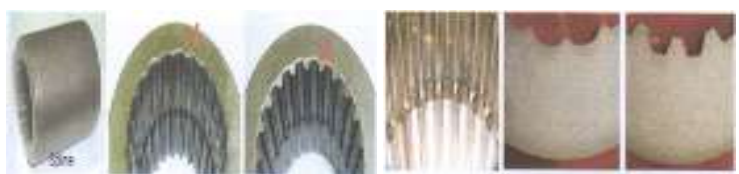

Gambar 13. Roda gigi spline yang mengalami kerusakan dan yang tidak mengalami kerusakan.
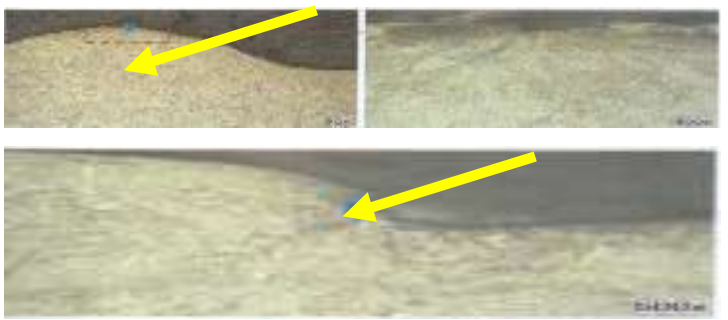

Gambar 14. Spline roda gigi yang bergesekan dengan shaft pada daerah antara yang rusak dan tidak rusak.

Berdasarkan hasil pengujian struktur mikro seperti terlihat gambar 14 diatas (perbesaran 50 dan $500 \mathrm{x}$ ), diidentifikasikan pada lokasi 1 dan 2 menunjukkan serpihan patah akibat beban gesek. Struktur mikro didaerah puncak roda gigi yang mengalami pengerasan berupa martensit dan dibagian tengah berupa martensit - bainit. Etsa: nital $2 \%$.

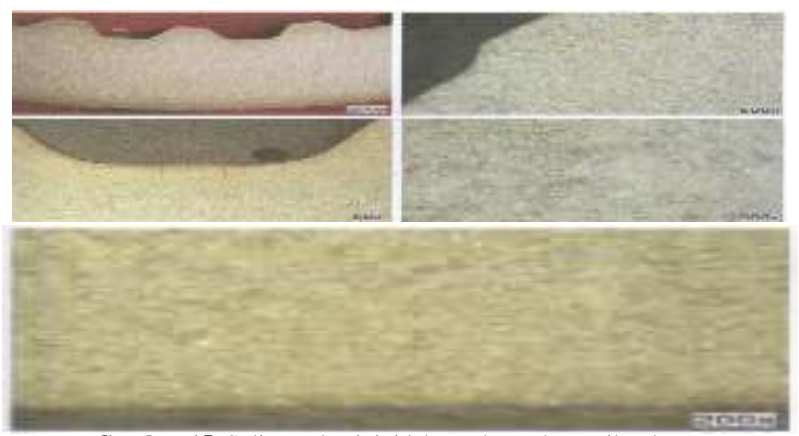

Gambar 15. Spline roda gigi tidak rusak, struktur mikro berupa martensit.
Logam yang dikenai tegangan berulang bisa mengalami kerusakan pada tegangan jauh lebih rendah dibanding tegangan yang dibutuhkan untuk perpatahan pada penerapan beban tunggal. Dalam ilmu metalurgi, kondisi itu disebut dengan kegagalan lelah (fatigue failure). Umumnya, kegagalan lelah terjadi pada bendabenda yang telah bekerja dalam waktu lama.

Kegagalan lelah acapkali terjadi ada alat-alat yang bekerja terus-menerus, terutama bagian yang menerima beban berulang dan getaran. Dieter (1992:1) menegaskan hampir 90 proses benda mekanis mengalami kegagalan lelah sehingga para perancang mesin harus memasukkan perhitungan kekelahan logam saat merencanakan bagian itu.

Kegagalan lelah sangat membahayakan karena biasanya tidak disertai dengan petunjuk awal. Kelelahan mengakibatkan logam terlihat rapuh, namun tanpa adanya deformasi pada struktur patahan. Bila diteliti pada skala maroskopik, kita bisa menemuka bagian halus dan kasar pada permukaan patahan. Bagian yang halus muncul akibat gesekan yang terjadi saat retak merambat dan bagian kasar muncul akibat perpatahan ulet yang terjadi saat penampang tidak dapat menerima beban.

Perkembangan retakan akibat kegagalan lelah biasanya ditandai oleh sejumlah cincin atau "garis pantai" (beach mark) yang bergerak ke dalam titik dimana kegagalan mulai terjadi. Ciri-ciri kelelahan lainnya, suatu kegagalan biasanya terjadi pada bagian di mana terdapat konsentrasi tegangan, seperti sudut tajam atau takik. Bisa juga terjadi pada tempat di mana terdapat konsentrasi tegangan metalurgis, seperti inklusi.

Dieter dalam bukunya Mechanical Metallurgy (1992) menjelaskan ada tiga faktor yang diperlukan agar terjadi kegagalan lelah, yaitu (1) tegangan tarik maksimum yang cukup tinggi, (2) variasi atau fluktuasi tegangan yang cukup besar, dan (3) siklus penerapan tegangan cukup besar. Dari hasil pengujian Makrografi tersebut dapat disimpulkan bahwa Gigi Penggerak dan Roda Gigi Spline mengalami keausan karena adanya gaya tekan yang berulang (beban dinamis) menyebabkan kelelahan pada permukaan. Akibat siklus beban yang rendah, kerusakannya seringkali berbentuk pits (sumuran) atau sebagian material mengalami retak (crack) atau serpihan patah / lipatan dan terlepas (spalling). Awal keretakan seringkali disebabkan oleh perubahan fasa / struktur akibat siklus tegangan kontak atau akibat inklusi yang berada sedikit dibawah permukaan (sub-surface inclusion). Keausan 
yang dialami oleh gigi penggerak dan roda gigi spline adalah keausan lelah (fatigue wear).

\subsection{Hasil pengujian kekerasan (hardness test)}

Objek : Poros motor final drive

Bahan : Steel

Mesin Uji : Frank Finotest

Standar Uji : SNI 19-0409-1989

Permukaan : Etching

Metode Uji : Vickers (HV)

$\mathrm{P}=5 \mathrm{kgf}, \alpha=136^{0}$

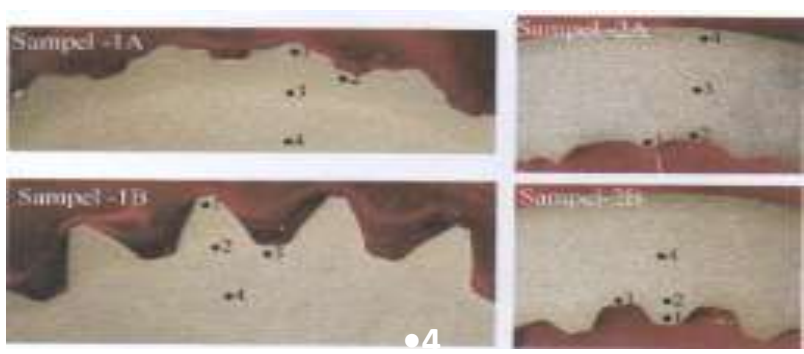

Gambar 16. Sampel pengujian kekerasan gigi penggerak

Pengujian kekerasan bahan sampel 1 dan 2 masing - masing penampang pada 4 (empat) titik pengujian dilakukan dengan metode vickers dengan beban $\mathrm{P}=5 \mathrm{Kgf}$, dan didapat hasil sebagai berikut :

Tabel 2.

Hasil uji kekerasan gigi penggerak

\begin{tabular}{cccccc}
\hline \multicolumn{5}{c}{ Nilai Kekerasan Vickers (HV) } \\
No & \multicolumn{4}{c}{ P, 5 kgf } & \\
\cline { 2 - 5 } & Sample & Sample & Sample & Sample & \\
& $1-A$ & $1-B$ & $2-A$ & $2-B$ & \\
\hline 1 & 632 & 676 & 687 & 576 \\
2 & 602 & 423 & 665 & 550 & \\
3 & 293 & 653 & 412 & 642 & \\
4 & 290 & 429 & 653 & 371 & \\
\hline
\end{tabular}

Rata - rata kekerasan pada permukaan puncak gigi penggerak (kulit luar) dan isi (dalam) yaitu

Untuk Sampel 1-A

○ Posisi pengujian 1 dan $2(632+602)=$ 1234/2 = 617 HV (Through Hardening)

- Posisi pengujian 3 dan $4(293+290)=$ $583 / 2=292 \mathrm{HV}$

Untuk Sampel 1-B

○ Posisi pengujian 1 dan $3(676+653)=$ 1329/2 = 665 HV (Through Hardening)

- Posisi pengujian 2 dan $4(423+429)=$ $852 / 2=426 \mathrm{HV}$

Untuk Sampel 2-A

- Posisi pengujian 1 dan $2(687+665)=$ 1352/2 = 676 HV (Through Hardening)
- Posisi pengujian 3 dan $4(412+653)=$ $1065 / 2=533 \mathrm{HV}$

\section{Untuk Sampel 2-B}

○ Posisi pengujian 1 dan $3(576+642)=$ 1218/2 = 609 HV (Through Hardening)

○ Posisi pengujian 2 dan $4(550+371)=$ $921 / 2=461 \mathrm{HV}$

Nilai kekerasan bahan pada sampel 1-A disisi area penerima beban pada puncak gigi (yang mengalami keausan) adalah dengan rata rata $617 \mathrm{HV}$, sementara disisi yang tidak menerima beban dengan rata - rata $292 \mathrm{HV}$

Nilai kekerasan bahan pada sampel 1-B disisi area penerima beban pada puncak gigi (yang mengalami keausan) adalah dengan rata rata $665 \mathrm{HV}$, sementara disisi yang tidak menerima beban dengan rata - rata $426 \mathrm{HV}$

Nilai kekerasan bahan pada sampel 2-A disisi area penerima beban pada puncak gigi (yang mengalami keausan) adalah dengan rata rata $676 \mathrm{HV}$, sementara disisi yang tidak menerima beban dengan rata - rata $533 \mathrm{HV}$

Nilai kekerasan bahan pada sampel 2-B disisi area jenerima beban pada puncak gigi (yang mengalami keausan) adalah dengan rata rata $609 \mathrm{HV}$, sementara disisi yang tidak menerima beban dengan rata - rata $461 \mathrm{HV}$

Dari hasil analisis distribusi kekerasan bahan pada masing - masing titik dapat dijelaskan bahwa nilai kekerasan bahan gigi penggerak pada sampel 1-A dan B serta sampel 2-A dan B didaerah yang menerima beban (puncak gigi) berkisar 609, 617, 665 dan $676 \mathrm{HV}$ dengan rata - rata $642 \mathrm{HV}$, setara dengan (57,4 HRC).

Dari literatur diketahui bahwa standard kekerasan Baja Paduan Rendah (Low Alloy Steel) termasuk dalam kelas ThroughHardening Low Alloy Steel Bar 4140, dengan kekerasan permukaan 58 HRC, dengan demikian nilai kekerasan bahan gigi penggerak memenuhi standar kekerasan sesuai dengan spesifikasi yaitu kisaran 600 - 650 HV (mendekati rata - rata kekerasan $642 \mathrm{HV}$ ) (equivalent dengan 57,4 HRC). Baja AISI 4140 adalah baja karbon sedang, digunakan untuk jenis baja yang membutuhkan kekuatan tinggi. Oleh karenanya untuk dapat meningkatkan ketangguhan kekerasan dan kekuatan yang baik.

Jadi dapat disimpulkan bahwa kekerasan pada gigi penggerak baik karena pengaruh panas maupun deformasi menunjukkan bahwa tidak terjadi perubahan sifat mekanik bahan selama pemakaian. Dengan demikian nilai kekerasan bahan gigi penggerak memenuhi standard kekerasan baja AISI 4140. 


\subsection{Analisis penyebab dan mekanisme} kerusakan.

Penyebab utama terjadinya kerusakan dan keausan gigi penggerak dan roda gigi spline adalah karena adanya gesekan beban putar, gaya tekan yang berulang (beban dinamis) yang dialami pada kondisi operasional dikarenakan fungsi dari poros motor final drive adalah mereduksi putaran dan meningkatkan torsi. Pada proses kerjanya poros motor final drive dihadapkan pada tekanan permukaan yang besar yang disebabkan oleh beban goncangan dan benturan. Konsentrasi tegangan terjadi pada daerah yang mempunyai luas permukaan kecil.

3.8. Penanggulangan dan usaha pencegahan gigi penggerak dan roda gigi spline mengalami keausan / kerusakan.

1. Keausan material akibat fatigue dapat diminimumkan dengan mencegah terbentuknya microcrack pada material.

2. Peningkatan kekerasan permukaan dapat mencegah deformasi sub-surface dan memperlambat crack nucleation rate.

3. Peningkatan ketangguhan material dapat menurunkan crack growth rate.

4. Pada umumnya setiap manipulasi mikrostruktur untuk meningkatkan kekerasan selalu diikuti dengan penurunan ketangguhan. Strateginya adalah bagaimana mendapatkan kekuatan dan kekerasan material yang tinggi tanpa menurunkan ketangguhannya secara signifikan.

5. Seperti pada upaya-upaya sebelumnya, ketahanan aus akigat fatigue dapat juga ditingkatkan dengan memberikan pelapisan material yang keras pada material yang lunak.

6. Karena pada umumnya zona deformasi plastis jarang sekali terjadi pada kedalaman lebih dari 200 mikron, maka tebal lapisan minimum harus sekitar angka tersebut.

\subsection{Mengatasi keausan dengan pertimbangan materialnya.}

Menggunakan material yang memiliki resistensi terhadap deformasi plastis serta mampu menghindari terjadinya retak nukleasi dan pertumbuhan, yaitu material yang mempunyai kekerasan tinggi dan ketangguhan.

\section{Simpulan}

Berdasarkan hasil pengolahan dan analisis data yang telah dilakukan diatas dapat dijelaskan bahwa :
1. Dari hasil pemeriksaan visual dengan foto makro gigi penggerak dan roda gigi spline terlihat bahwa pada gigi penggerak mengalami keausan akibat gesekan beban putar, dan pada roda gigi spline terlihat adanya serpihan patah akibat beban gesek.

2. Dari hasil pengujian Makrografi tersebut dapat disimpulkan bahwa Gigi Penggerak dan Roda Gigi Spline mengalami keausan karena adanya gaya tekan yang berulang (beban dinamis) menyebabkan kelelahan pada permukaan

3. Keausan yang dialami oleh gigi penggerak dan roda gigi spline adalah keausan lelah (fatigue wear) dan kegagalan lelah (fatigue failure).

4. Dari hasil analisis distribusi kekerasan bahan pada masing - masing titik dapat dijelaskan bahwa nilai kekerasan bahan gigi penggerak pada sampel 1-A dan B serta sampel 2-A dan B didaerah yang menerima beban (puncak gigi) berkisar 609, 617, 665 dan 676 $\mathrm{HV}$ dengan rata - rata $642 \mathrm{HV}$, setara dengan (57,4 HRC). Dari literatur diketahui bahwa standard kekerasan Baja Paduan Rendah (Low Alloy Steel) termasuk dalam kelas Through-Hardening Low Alloy Steel Bar 4140, dengan kekerasan permukaan 58 HRC, dengan demikian nilai kekerasan bahan gigi penggerak memenuhi standar kekerasan sesuai dengan spesifikasi yaitu kisaran 600 - $650 \mathrm{HV}$ (mendekati rata - rata kekerasan $642 \mathrm{HV}$ ) (equivalent dengan 57,4 HRC).

\section{Saran}

Disarankan untuk menggunakan material yang memiliki resistensi terhadap deformasi plastis serta mampu menghindari terjadinya retak nukleasi dan pertumbuhan, yaitu material yang mempunyai kekerasan tinggi dan ketangguhan.

Pastikan operator mengecek oli final drive setiap hari, dan pastikan tidak terjadi kebocoran pada floating seal, apabila itu terjadi sebaiknya lakukan penggantian floating seal, jangan memaksakan unit tersebut beroperasi, karena kemungkinan terburuknya, final drive akan berputar tanpa pelumasan,, dan itu akan menyebabkan kerusakan parah.

\section{Daftar Pustaka}

1. American National Standar, "Gear Materials and Heat Treatment Manual", AGMA 2004 - B89, Revision of AGMA 240.01 . 
2. ASM Metal Handbook Volume 11, "Failure Analysis and Preventive".

3. ASM Metal Handbook Volume 18, "Friction, Lubrication, and Wear Technology".

4. Ahmad Zainuri, ST, M.Eng., Diktat Elemen Mesin III, Teknik Mesin Universitas Mataram, 2011.

5. D.A. Porter and K.E. Easterling, 2005, Phase Transformation in Metals and Alloys, second edition,

6. Djoko Wiyono, 2000, Failure Analysis, program Pasca Sarjana Magister Teknim Mesin ISTN, Jakarta

7. Edi Agus Basuki., 2005, Transformasi Fasa Lanjut, Institut Teknologi Bandung, Bandung.

8. G. Blake, M. Margetts and W. Silver Thorne, Gear Failure Analysis Involving Grinding Burn.

9. Glyn Meyrick, 2001, Physical Metallurgy of Steel, class note and lecture material,

10. Imam Syafa'at, Permodelan keausan Steady State, Universitas Diponegoro Semarang, 2010.

11. Ir. Teguh Raharjo, MT., Diktat Analisa Kegagalan Material, Institut Teknologi Nasional Malang, 2010.

12. Ilham Hatta, Aplikasi Mikro Analisis dan Fraktografi untuk menentukan Kualitas Produk dan Penyebab Kerusakan Suatu Komponen, Prosiding Pertemuan Ilmiah Ilmu Pengetahuan dan Teknologi Bahan, Serpong, 2012

13. T. Hafli, Perilaku Kegagalan Roda Gigi Lurus Akibat Beban Fatik dan Impak, USU, 2006.

14. Vineat Pandey, Failure Analysis of Gear Material, Materials Science and Engineering, Master of Technology (M.Tech). 